\title{
Quantitative liver function tests: A realizable goal?
}

\author{
Denis J MORGan, MPharm, PhD, Susan L Elliott, MB,BS, FRACP, hany GHabrial, BSc, PhD, \\ RICHARD A SMALLWOOD, MD, FRACP
}

DJ Morgan, SL ElliotT, H GHABRial, RA SMAllwoOd. Quantitative liver function tests: A realizable goal? Can J Gastroenterol 1991;5(2):77-81. A variety of tests has been used to assess liver function and predict hepatic functional reserve in patients with liver disease. These tests comprise clinical assessment, simple biochemical measurements and so-called 'quantitative' tests of liver function, ie, elimination rate measurements of exogenous markers such as drugs and other compounds. So far no single test or group of tests has proved to be a sufficiently sensitive and accurate measure of overall hepatic function across the whole spectrum of liver disease. This may be due to diversity in the hepatic handling of these compounds and in changes in architecture, hemodynamics and cell function in liver disease. The absence of a satisfactory test emphasizes the value of clinical assessments (eg, the Child-Turcotte or ChildPugh classifications), because of their relative simplicity.

Key Words: Liver disease, Liver function, Quantitative tests

\section{Épreuves fonctionnelles hépatiques quantitatives: Un objectif réalisable?}

RESUME: Diverses épreuves permettent d'évaluer la fonction hépatique et de prédire les réserves fonctionnelles des patients porteurs d'affections hépatiques. Parmi ces tests figurent l'examen clinique, les simples mesures biochimiques et les épreuves dites "quantitatives" de la fonction hépatique (qui mesurent le taux d'élimination des marqueurs exogènes tels que les médicaments et autres substances). Jusqu'à présent, il n'existe aucune épreuve unique ou groupe de tests suffisamment sensibles ou exacts pour mesurer la fonction hépatique pour toute la gamme d'affections du foie. La situation peut être attribuable à la diversité des mécanismes hépatiques à l'oeuvre et aux divers changements qui affectent l'architecture, l'hémodynamisme et la fonction hépatocellulaire. Le fait qu'on ne dispose pas d'épreuves satisfaisantes augmente encore la valeur des examens cliniques (ex: les classifications de Child-Turcotte ou de Child-Pugh), à cause de leur relative simplicité.

Victorian College of Pharmacy, Melboume; and University of Melboume, Department of Medicine, Repatriation General Hospital, Heidelberg, Victoria, Australia

Correspondence and reprints: Dr DJ Morgan, Victorian College of Pharmacy, 381 Royal Parade, Parkville, Victoria, Australia 3052

Received for publication October 8, 1990. Accepted February 13, 1991
PHRONICLIVER DISEASE COMPRISES an assortment of disorders in which there may be varying degrees of change in organ structure, hemodynamics and cell function. Over the years many different methods have been proposed for obtaining quantitative information regarding the extent of liver dysfunction and progression of the disease. Ideally, what is required is a hepatologist's counterpart to creatinine clearance, which maintains a reliable and predictable relationship to renal functional reserve throughout the course of progressive renal impairment. It is therefore possible to predict with reasonable accuracy when renal dialysis or transplantation will become necessary.

The first measures adopted to assess hepatic function in patients with chronic liver disease were based on clinical features and routine biochemical tests. Development of tests with certain exogenous substances - such as galactose and indocyanine green - followed. More recently there has been interest in selected drugs for measuring hepatic function $(1,2)$, since hepatic drug elimination may be impaired in patients with established liver disease $(3,4)$.

The introduction of liver transplantation has highlighted the need for a satisfactory quantitative test of hepatic 
functional reserve, in order to better define when transplant will be required. The course of chronic liver disease often makes the timing of transplantation difficult, since it can be erratic and punctuated by periods of sudden deterioration due to intercurrent gastrointestinal bleeding, infection or an alcoholic binge. In this article the various approaches to assessing liver function in chronic liver disease will be reviewed, with emphasis on the socalled 'quantitative' tests.

\section{FACTORS AFFECTING ELIMINATION OF SUBSTRATES BY THE LIVER}

Hepatic elimination requires initial uptake of the substance into the liver cell from sinusoidal blood via the space of Disse, followed by transport within the hepatocyte, and finally metabolism by hepatic enzymes or secretion of the unchanged compound into bile. Impairment of hepatic elimination may involve one or more of these steps, but it is the final step which is normally rate limiting. The capacity of this final elimination process (ie, metabolism or biliary excretion) is very high for some substances and very low for others. If the capacity is very high, then hepatic clearance will be largely dependent on hepatic bloodflow and independent of elimination capacity (intrinsic clearance). If the elimination capacity is low, hepatic clearance will be independent of hepatic bloodflow but will depend on intrinsic clearance (5). For compounds in this latter category that are highly bound to plasma proteins, hepatic clearance will also depend on the degree of protein binding (6).

These considerations indicate that there are several potential mechanisms by which hepatic elimination could be changed.

\section{PATHOPHYSIOLOGY OF CHRONIC LIVER DISEASE}

There is a variety of functional and structural changes that may occur in chronic liver disease (7). The synthetic function of the liver may be compromised, with impaired production of export proteins such as albumin, alpha-1 acid glycoprotein and clotting factors.
A reduction in plasma concentrations of albumin and alpha-1 acid glycoprotein leads to a reduction in the extent of plasma protein binding of otherwise highly protein bound drugs and other compounds $(8,9)$.

There is also a reduction in the various metabolic functions of the liver. Of special interest are the hepatic mixed function oxidase enzymes, which are responsible for the oxidation of many drugs and a wide variety of other compounds. There is a reduction in the hepatic content of cytochrome P450, an essential component of the mixed function oxidase system (10-13). This is reflected in reduced in vitro oxidation rates of many substrates $(10,11)$. However, it is now recognized that cytochrome P450 is a family of isoenzymes, and that the effect of cirrhosis on the hepatic content of each isoenzyme is not necessarily the same (11).

Another important change in chronic liver disease is alteration of the liver's microcirculation. In the healthy liver, the endothelial cells lining the sinusoids are perforated by a multitude of fenestrae, which allow free access of solutes and particles to the space of Disse, and thus to the liver cell. In chronic liver disease one finds a striking reduction in the number of fenestrae, deposition of collagen in the space of Disse and formation of a basal lamina beneath the endothelial cells (14-16). These changes transformed the sinusoids into capillary-like structures with decreased access of small molecules into the space of Disse, and hindered uptake by the liver (17-20).

Finally, functional hepatic bloodflow may be reduced as a result of intraor extrahepatic shunting of blood, which thereby reduces the delivery of substances in blood to the liver cell (7).

\section{CLINICAL INDICES AND CONVENTIONAL LIVER FUNCTION TESTS}

The simplest assessment of liver function involves a combination of clinical features (eg, neurological state, presence of ascites) and simple biochemical tests (eg, serum bilirubin, serum albumin, prothrombin time) $(21,22)$. This approach is not entirely satisfactory because of observer error, a lack of independence among individual variables (23) and a dependence on other factors unrelated to the liver. Moreover, certain variables (eg, transaminase enzymes) may be normal even though liver disease is advanced. These indices, while providing a means of standardizing severity to permit comparison of different patient groups, have been considered too imprecise for determining the timing of liver transplantation in the individual patient.

To predict prognosis more reliably, models have been devised which apply statistical methods to combinations of conventional clinical, biochemical and histological data to form a prognostic index. These mathematical models have been applied to several diseases, in particular to primary biliary cirrhosis (24-26) and primary sclerosing cholangitis (27). They have all used the Cox proportional hazards multivariate regression procedure for data obtained from clinical trials (28). Not surprisingly, the models use similar risk variables (age and serum bilirubin are common to all and seem to have the greatest impact). Two models for primary biliary cirrhosis have been tested and found to be highly correlated in their assessment of patient risk $(r=0.92)(25,26)$. However, even within specific disease groups, the models do not yield a precise prognosis for a given individual (29).

A disadvantage of each of these models is that they use data recorded at only one time period in what is usually a long disease course. Although the overall course of cholestatic diseases such as primary biliary cirrhosis and primary sclerosing cholangitis is one of progressive decline, it may occur in a 'stepwise' manner rather than as a smooth decline. Accordingly, as suggested by Christensen (29), the predictive power of a model could be increased if it encompassed follow-up data in its analysis.

\section{QUANTITATIVE LIVER FUNCTION TESTS}

A possible alternative to these indirect statistical analyses is the use of so-called 'quantitative' liver function tests, ie, tests of the capacity of the liver 
to eliminate marker compounds. Some of these tests use exogenous test compounds such as galactose (30-33), indocyanine green $(1,34,35)$, bile acids (36-38) and sorbitol (39). The compound is injected either as a bolus or as a prolonged infusion, and measurement is made of a single plasma concentration of substrate or of several concentrations over an appropriate period. Even more simply, in the case of bile acids the postprandial plasma concentration of endogenous bile acids is measured (38).

All of these substances are characterized by high hepatic clearance at the low doses used, so that their elimination rates predominantly reflect hepatic bloodflow rather than the capacity of the elimination process. They have found widespread application, therefore, as indices of hepatic bloodflow $(30,33-35,39-42)$. At high doses sufficient to saturate hepatic elimination processes, galactose and indocyanine green have also been used as measures of elimination capacity, because at a high dose, elimination depends more on elimination capacity than on bloodflow $(1,31,40)$. Each of these test substances depends on a different process for its hepatic elimination, eg, galactose depends on the cytosolic enzyme galactokinase, and indocyanine green and bile acids depend on biliary excretion mechanisms.

Several drugs have been used as quantitative markers of liver function. These include antipyrine (43-45), aminopyrine $(46,47)$, caffeine (48), phenacetin (49) and diazepam (50). All are eliminated entirely by hepatic metabolism, oxidation being the main pathway. They have low hepatic clearance; therefore, their elimination rates reflect the capacity of hepatic drug oxidation systems rather than hepatic bloodflow. The test may be performed by measuring systemic clearance of the drug by collecting multiple blood or saliva samples after ingestion of a single oral dose. Alternatively, carbon-14labelled drug may be administered and the excretion rate of ${ }^{14} \mathrm{CO}_{2}$ in expired air used as a measure of the rate of hepatic metabolism (46,49-52).

The metabolism of these drugs is carried out by different hepatic enzymes.
The principal enzyme system responsible, cytochrome P450, is a family of at least 20 separate isoenzymes (53). Even the oxidation of a single drug does not usually reflect the activity of a single isoenzyme. For example, caffeine is metabolized to at least 11 metabolites, and numerous cytochrome $\mathrm{P} 450$ isoenzymes are involved (54).

Moreover, the metabolism of these drugs is not representative of other major metabolic pathways in the liver, for example, drug conjugation processes. Conjugation seems to be much less affected in liver disease than oxidation (55).

A further complicating factor is the wide variability in the handling of drugs even in healthy persons with normal livers. There may be a several 100 -fold difference among normal individuals in their ability to metabolize a given drug (56).

\section{EVALUATION OF QUANTITATIVE LIVER FUNCTION TESTS}

The effect of liver disease on the hepatic disposition of many drugs and other compounds has been examined $(3,4,6,9)$.

Sensitivity of tests in detecting impaired function: Ideally, a quantitative liver function test ought to determine the severity of hepatic impairment in all forms of chronic liver disease. Most of the available data have been obtained in patients with alcoholic cirrhosis, with few data available for other diseases such as chronic active hepatitis, primary biliary cirrhosis or sclerosing cholangitis $(3,4)$. With isolated exceptions $(57,58)$, quantitative tests of hepatic function generally appear normal until the disease is at an advanced stage and decompensated cirrhosis is present (59-64).

Studies with test compounds such as antipyrine (45,62,65-69), aminopyrine $(61,62)$, caffeine $(54,70)$, indocyanine green $(23,45,62)$ and galactose $(45)$ show impairment of hepatic function only in patients with advanced cirrhosis. A complicating factor is, however, that even in advanced cirrhosis elimination of some drugs is normal, eg, those metabolized by glucuronidation
$(55,71,72)$. An exception is theophylline, the elimination of which is impaired in apparently well compensated cirrhosis (64).

Accuracy of tests in measuring hepatic function: Although there is a broad correlation among results from various markers in patients with cirrhosis, there is a great deal of variation in the degree of impairment of elimination with different markers in the same patient. Even for markers that are eliminated by similar pathways, eg, by oxidative metabolism, there is still a disparity in test results $(62,63,66,68,69,73)$. Studies with multiple markers in the same patient indicate that correlations among results with individual markers may not be sufficiently strong to allow the result with any one marker to predict the result of the others $(45,62,64,73)$.

It is also of interest to compare results obtained with exogenous markers to those obtained with endogenous markers. In some studies, results with caffeine, theophylline and indocyanine green have correlated well with those of tests such as serum albumin, serum bilirubin, prothrombin time and Child-Pugh criteria $(23,74$, 75). However, these correlations are again not sufficiently strong to be of predictive value. There are also studies in which results with theophylline, lidocaine (64), antipyrine (73), galactose (74) and fluxotene (76) did not correlate with tests with endogenous markers or clinical criteria. Furthermore, a study evaluating the aminopyrine breath test in cirrhotics found that the test added no predictive ability above that of the Child-Turcotte classification (77).

\section{CONCLUSION}

The present evidence suggests that it is unrealistic to expect one simple test to predict the course and outcome of all chronic liver disease. Nevertheless it may turn out that antipyrine clearance, for example, will prove to be very helpful in predicting the course of chronic liver disease of one or perhaps all types, despite intuition and the above arguments. The onus is on the advocates of the various tests to establish their use- 
fulness empirically, as has been done for the various indices employing clinical criteria and conventional liver function tests.

Are patients coming to transplantation, hepatic resection or splenorenal shunt surgery without the benefit of regular assessment with quantitative liver function tests disadvantaged in some measurable way? Establishing the usefulness of a quantitative liver function test will require some form of objective assessment of outcome which shows that patients whose management is based on the results of the test are better off than those in whom the test is not used. As yet such an exercise has not been undertaken.

\section{REFERENCES}

1. Brody DH, Leichter L. Clearance tests of liver function. Med Clin North Am 1979;63:621-30.

2. Branch RA. Drugs as indication of hepatic function. Hepatology 1982;2:97-105.

3. Bass NM, Williams RL. Guide to drug dosage in hepatic disease. Clin Pharmacokin 1988;15:396-420.

4. Howden C, Birnie GG, Brodie MJ. Drug metabolism in liver disease. Phatmacol Ther 1989;40:439-74.

5. Wilkinson GR, Shand DG. A physiological approach to hepatic drug clearance. Clin Pharmacol Ther 1975; 18:377-90.

6. Blaschke TF. Protein binding and kinetics of drugs in liver disease. Clin Pharmacokin 1977;2:32-44.

7. Sherlock S. Diseases of the Liver and Biliary System, 8th edn. Oxford: Blackwell Scientific Publications, 1989:410-24.

8. Rothschild MA, Oratz M, Schreiber SS. Serum albumin. Hepatology 1988;8:385-401.

9. Kremer JMH, Wilting J, Janssen LHM. Drug binding to human alpha-1-acid glycoprotein in health and disease. Pharmacol Rev 1988;40:1-47.

10. Sotaniemi EA, Pelkonen RO, Puukka M. Measurement of hepatic drugmetabolising enzyme activity in man. Comparison of three different assays. Eur J Clin Pharmacol 1980;17:267-74.

11. Murray M, Zaluzny L, Farrell GC. Drug metabolism in cirrhosis. Selective changes in cytochrome P450 isozymes in the choline-deficient rat model. Biochem Pharmacol 1986;35:1817-24.

12. Pirttiaho HI, Sotaniemi EA, Ahlquist J, Pitkanen U, Pelkonen RO. Liver size and indices of drug metabolism in alcoholics. Eur J Clin Pharmacol
1978;13:61-7.

13. Pirttiaho $H$. Liver size in evaluating drug metabolizing capacity in man. Int Clin Pharmacol Biopharm 1979;17:271-6.

14. Henriksen JH, Horn T, Christoffersen $\mathrm{P}$. The blood-lymph barrier in the liver: A review based on morphological and functional concepts of normal and cirrhotic liver. Liver 1984;4:221-32.

15. Horn T, Christoffersen P, Henriksen IH. Alcoholic liver injury: Defenestration in noncirrhotic livers A scanning electron microscopic study. Hepatology 1987;7:77-82.

16. Lieber CS. Pathophysiology of alcoholic liver disease. Mol Aspects 1988;10:107-46.

17. Huet PM, Goresky CA, Villeneuve JP, Marleau D, Lough JO. Assessment of liver microcirculation in human cirrhosis. J Clin Invest 1982;70:1234-44.

18. Varin F, Huet PM. Hepatic microcirculation in the perfused cirrhotic rat liver. J Clin Invest 1985;76:1904-12.

19. Reichen J, Le M. Sinusoidal capillarization is more important than intrahepatic shunting to explain decreased propranolol clearance in liver cirrhotic rats. Gastroenterology 1983;84:1283. (Abst)

20. Reichen J. Hepatic spaces and transport in the perfused liver. In: Petzinger E, Kinner K-H, Sies H, eds. Hepatic Transport in Organic Substances. Berlin: Springer-Verlag, 1989:45-56.

21. Child CG. The Liver and Portal Hypertension. Philadelphia: WB Saunders, 1964:50.

22. Pugh RNH, Murray-Lyon IM, Dawson JL, Pietroni MC, Williams R. Transection of the oesophagus for bleeding oesophageal varices. $\mathrm{Br}$ J Surg 1973;60:646-9.

23. Barbare JC, Poupon RE, Jaillon P. Prod'homme S, Darnis P, Poupon RY. Intrinsic hepatic clearance and Child-Turcotte classification for assessment of liver function in cirrhosis. Hepatology 1985; 1:253-9.

24. Roll J, Boyer JL, Barry D, Klatskin MD. The prognostic importance of clinical and histologic features in asymptomatic and symptomatic primary biliary cirrhosis. N Engl J Med 1983;308:1-7.

25. Christensen E, Neuberger I, Crowe J, et al. Beneficial effect of azathioprine and prediction of prognosis in primary biliary cirrhosis. Final results of an international trial. Gastroenterology 1985;89:1084-91.

26. Dickson ER, Grambsch PM, Fleming TR, Fisher LD, Langworthy A. Prognosis in primary biliary cirrhosis:
Model for decision making. Hepatology 1989;10:1-7.

27. Wiesner RH, Gramsch PM, Dickson ER, et al. Primary sclerosing cholangitis: Natural history, prognostic factors and survival analysis. Hepatology 1989;10:430-6.

28. Cox DR. Regression models and life-tables (with discussion). J R Stat Soc (B) 1972;34:187-202.

29. Christensen E. Prognostication in primary biliary cirrhosis: Relevance to the individual patient. Hepatology 1989;10:111-3.

30. Tygstrup N, Winkler K. Galactose blood clearance as a measure of hepatic blood flow. Clin Sci 1958;17:1-9.

31. Tygstrup N. Determination of the hepatic elimination capacity (LM) of galactose by single injection. Scand J Clin Lab Invest 1966;18(Suppl 92): 118-25.

32. Shreeve WW, Shoop JD, Ot DG. Test for alcoholic cirrhosis by conversion of $\mathrm{C}$ - or C-galactose to expired $\mathrm{CO}_{2}$. Gastroenterology 1976;71:98-101.

33. Henderson JM, Kutner MH, Bain RP. First-order clearance of plasma galactose: The effect of liver disease. Gastroenterology 1982;83:1090-6.

34. Wiegard BD, Keterer SG, Rapaport E. The use of indocyanine green for the evaluation of hepatic function and blood flow in man. Disease 1960;5:427-36.

35. Caesar ], Shaldon S, Chiandussi L, Guevara L, Sherlock S. The use of indocyanine green in the measurement of hepatic blood flow and as a test of hepatic function. Clin $\mathrm{Sci}$ 1961;21:43-57.

36. Hofman AF. The aminopyrine breath test and serum bile acid level:

Nominated but not yet elected to join the common liver tests. Hepatology 1982;2;512-7.

37. Miescher G, Paumgartner G, Preisig R. Portal-systemic spill-over of bile acid: European study of mechanisms using ursodeoxycholic acid. Clin Invest 1983;13:439-45.

38. Islam S, Poupon RE, Barbare JC, Chretien Y, Darnis F, Poupon R. Fasting serum bile acid level in cirrhosis. A semi-quantitative index of hepatic function. J Hepatol 1985;1:609-17.

39. Zeeh J, Lange H, Bosch J, et al. Steady-state extrarenal sorbitol clearance as a measure of hepatic plasma flow. Gastroenterology 1988;95:749-59.

40. Keiding S. Hepatic clearance and liver flow. Hepatology 1987;4:393-8.

41. Skak C, Keiding S. Methodological problems in the use of indocyanine green to estimate hepatic blood flow and ICG clearance in man. Liver 
1987;7:155-62.

42. Keiding S. Galactose clearance measurements and liver blood flow. Gastroenterology 1988;94:477-81.

43. Branch RA, James JA, Read AE. The clearance of antipyrine and indocyanine green in normal subjects and in patients with chronic liver disease. Clin Pharmacol Ther 1976;20:81-9.

44. Vesell ES. The antipyrine test in clinical pharmacology: Conceptions and misconceptions. Clin Pharmacol Ther 1979;26:275-86.

45. Kawasaki S, Sugiyama Y, Iga T, et al. Hepatic clearance of antipyrine, indocyanine green, and galactose in normal subjects and in patients with chronic liver disease. Clin Pharmacol Ther 1988;44:217-24.

46. Hepner GW, Vesell ES. Assessment of aminopyrine metabolism in man by breath analysis after oral administration of ${ }^{14} \mathrm{C}$-aminopyrine. N Engl J Med 1974;291:1384-8.

47. Schneider JF, Baker AL, Haines NW. Aminopyrine $\mathrm{N}$-demethylation: A prognostic test of liver function in patients with alcoholic liver disease. Gastroenterology 1980;79:1145-50.

48. Renner E, Wietholtz $H$, Huguenin P, Arnaud MJ, Preisig R. Caffeine: A model compound for measuring liver function. Hepatology 1984:4:38-46.

49. Breen KJ, Bury RW, Calder I. A (C)-phenacetin breath test to measure hepatic function in man. Hepatology 1984:4:47-52.

50. Hepner GW, Vesell ES, Lipton A. Disposition of aminopyrine, antipyrine, diazepam and indocyanine green in patients with liver disease or on anticonvulsant therapy: Diazepam breath test and correlation in drug elimination. J Lab Clin Med 1977;90:440-56.

51. Bircher J, Kupfer A, Gikalov I, Preisig R. Aminopyrine demethylation measured by breath analysis in cirrhosis. Clin Pharmacol Ther 1976;20:484-92.

52. Wietholtz H, Voegelin M, Arnaud MJ. Measurement of cytochrome P-448 dependent liver enzyme system by a caffeine breath test. Eur ] Clin Pharmacol 1981;21:53-9.

53. Guengerich FP. Polymorphism of cytochrome $\mathrm{P} 450$ in humans. Trends Pharmacol Sci 1989;10:107-9.

54. Scott NR, Stambuk D, Chakraborty J, Marks V, Morgan MY. Caffeine clearance and biotransformation in patients with chronic liver disease. Clin Sci 1988; 74:377-94.

55. Ghabrial H, Desmond PV, Watson KJR, et al. The effects of age and chronic liver disease on the elimination for temazepam. Eur Clin Pharmacol 1986;30:93-7.

56. Mucklow JC. Environmental factors affecting drug metabolism. Pharmacol Ther 1988;36:105-17.

57. Birnie GG, McColl KEL, Thompson GG, Moore MR, Goldberg A, Brodie MJ. Antipyrine metabolism in acute hepatic porphyria in relapse and remission. $\mathrm{Br}$ Clin Pharmacol 1987;23:358-61.

58. Watt G, White NJ, Padre L, et al. Praziquantel pharmacokinetics and side effects in Schistosoma japonicum-infected patients with liver disease. Infect Dis 1988:157:530-5.

59. Williams RL, Blaschke TF, Meffin PJ, Melmon KL, Rowland M. Influence of viral hepatitis on the disposition of two compounds with high hepatic clearance: Lidocaine and indocyanine green. Clin Pharmacol Ther 1976;20:290-9.

60. Pessayre D, Lebrec D, Descatoire V, Peignoux M, Benhamou JP. Mechanism for reduced drug clearance in patients with cirrhosis. Gastroenterology 1978;74:566-71.

61. Monroe P, Baker A, Krager P, Schoeller D, Klein P. The aminopyrine breath test (ABT) predicts histology and correlates with course in patients with chronic hepatitis $(\mathrm{CH})$. Gastroenterology 1980;78:1314. (Abst)

62. Villeneuve JP, Thilbeault MJ, Ampelas $\mathrm{M}$, et al. Drug disposition in patients with $\mathrm{Hbs} \mathrm{Ag}$-positive chronic liver disease. Dig Dis Sci 1987;32:710-4.

63. Daneshmend TK, Homeida M, Kaye CM, Elamin AA, Roberts CJC. Disposition of oral metronidazole in hepatic cirrhosis and in hepatosplenic schistosomiasis. Gut 1982;23:807-13.

64. Colli A, Buccino G, Cocciolo M, Parravicini R, Scaltrino G. Disposition of a flow-limited drug (lidocaine) and a metabolic capacity-limited drug (theophylline) in liver cirrhosis. Clin Pharmacol Ther 1988;44:642-9.

65. Kirch W, Ohnhaus EE, Pabst J, Storstein L. Digitoxin in patients with hepatorenal insufficiency after repeated administration. Eur Heart ] 1989;10:40-7.

66. McQuinn RL, Pentikainen PJ, Chang
SF, Conard G. Pharmacokinetics of flecainide in patients with cirrhosis of the liver. Clin Pharmacol Ther 1988:44:566-72.

67. Mehta MU, Venkataramanan R, Burkart GJ, et al. Antipyrine kinetics in liver disease and liver transplantation. Clin Pharmacol Ther 1986:39:372-7.

68. Pentikainen PJ, Hietakorpi S, Halinen MO, Lampinen LM. Cirrhosis of the liver markedly impairs the elimination of mexiletine. Eur Clin Pharmacol 1986;30:83-8.

69. Pentikainen PJ, Valisalmi L, Himberg J], Crevoisier C. Pharmacokinetics of midazolam following intravenous and oral administration in patients with chronic liver disease and in healthy subjects. Clin Pharmacol 1989;29:272-7.

70. Scott NR, Stambuk D, Chakraborty ]. Marks V, Morgan MY. The pharmacokinetics of caffeine and its dimethylxanthine metabolites in patients with chronic liver disease. Br Clin Pharmacol 1989;27:205-13.

71. Ochs HR, Greenblatt DJ, VerburgOchs B, Matlis R. Temazepam clearance unaltered in cirrhosis. Gastroenterology 1986;81:80-4.

72. Crotty B, Watson KJR, Desmond PV, et al. Hepatic extraction of morphine is impaired in cirrhosis. Eur Clin Pharmacol 1989;36:501-6.

73. MacGilchrist AJ, Birnie GG, Cook A, et al. Pharmacokinetics and pharmacodynamics of intravenous midazolam in patients with severe alcoholic cirrhosis. Gut 1986;27:190-5.

74. Holstege A, Staiger M, Haag D, Gerok W. Correlation of caffeine elimination and Child's classification in liver cirrhosis. Klin Wochenschr 1989;67:6-15.

75. Kraan J, Jonkman JHG, Koeter GH, et al. The pharmacokinetics of theophylline and enprofylline in patients with liver cirrhosis and in patients with chronic renal disease. Eur J Clin Pharmacol 1988;35:357-62.

76. Schenker S, Bergstrom RF, Wolen RL, Lemberger L. Fluoxetine disposition and elimination in cirrhosis. Clin Pharmacol Ther 1988;44:353-9.

77. Villeneuve JP, Infante-Rivard C, Ampelas M, Pomier-Layrergues G, Huet PM, Marleau D. Prognostic value of the aminopyrine breath test in cirrhotic patients. Hepatology 1986;6:928-31. 


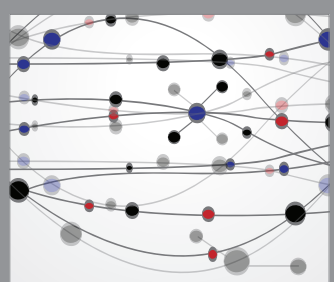

The Scientific World Journal
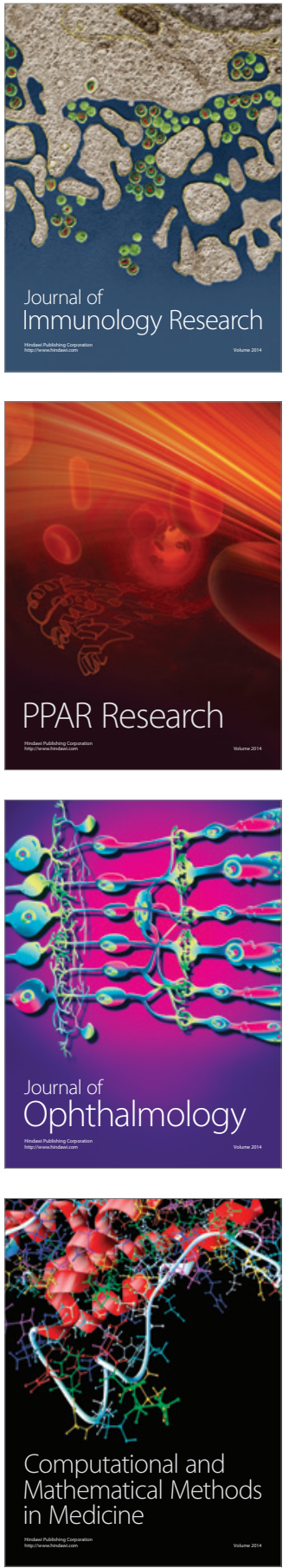

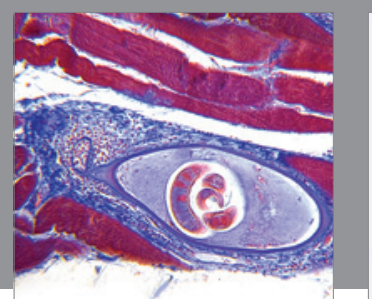

Gastroenterology Research and Practice

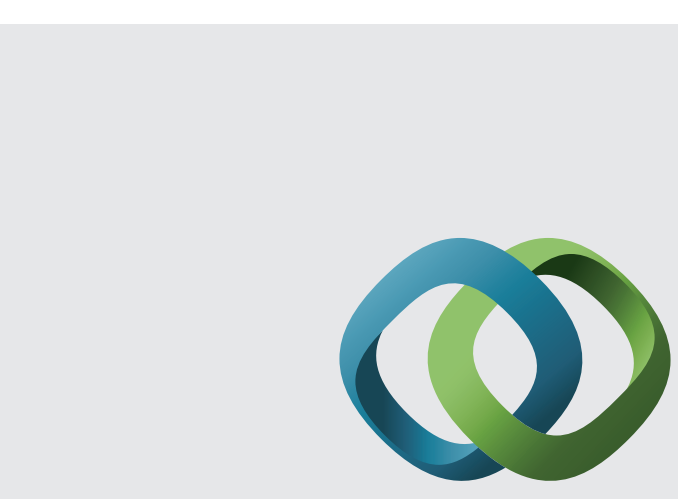

\section{Hindawi}

Submit your manuscripts at

http://www.hindawi.com
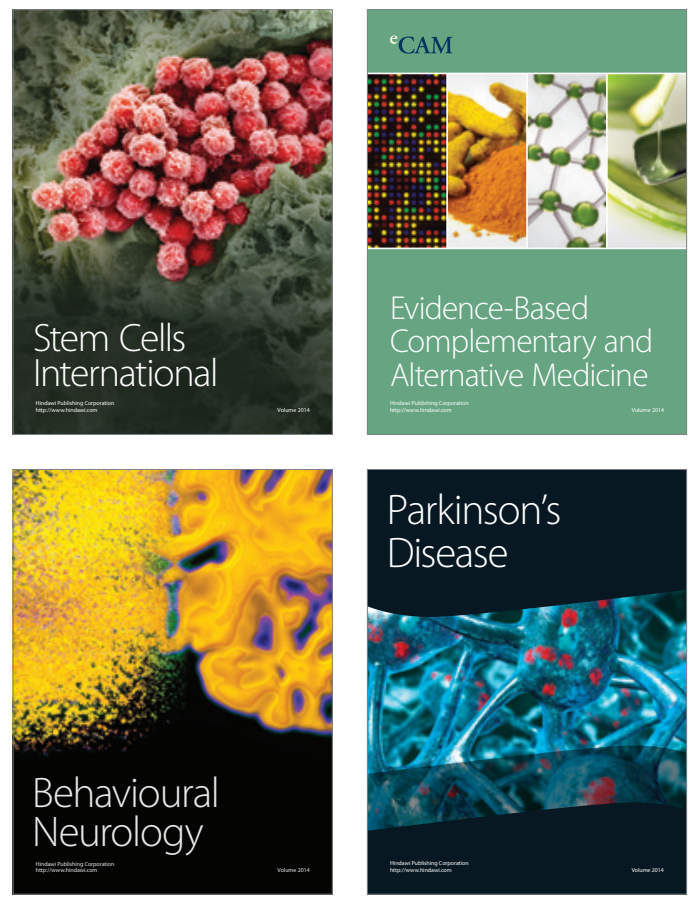
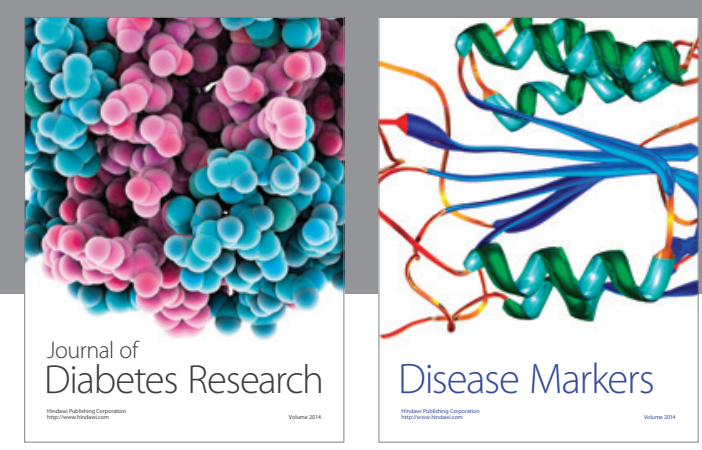

Disease Markers
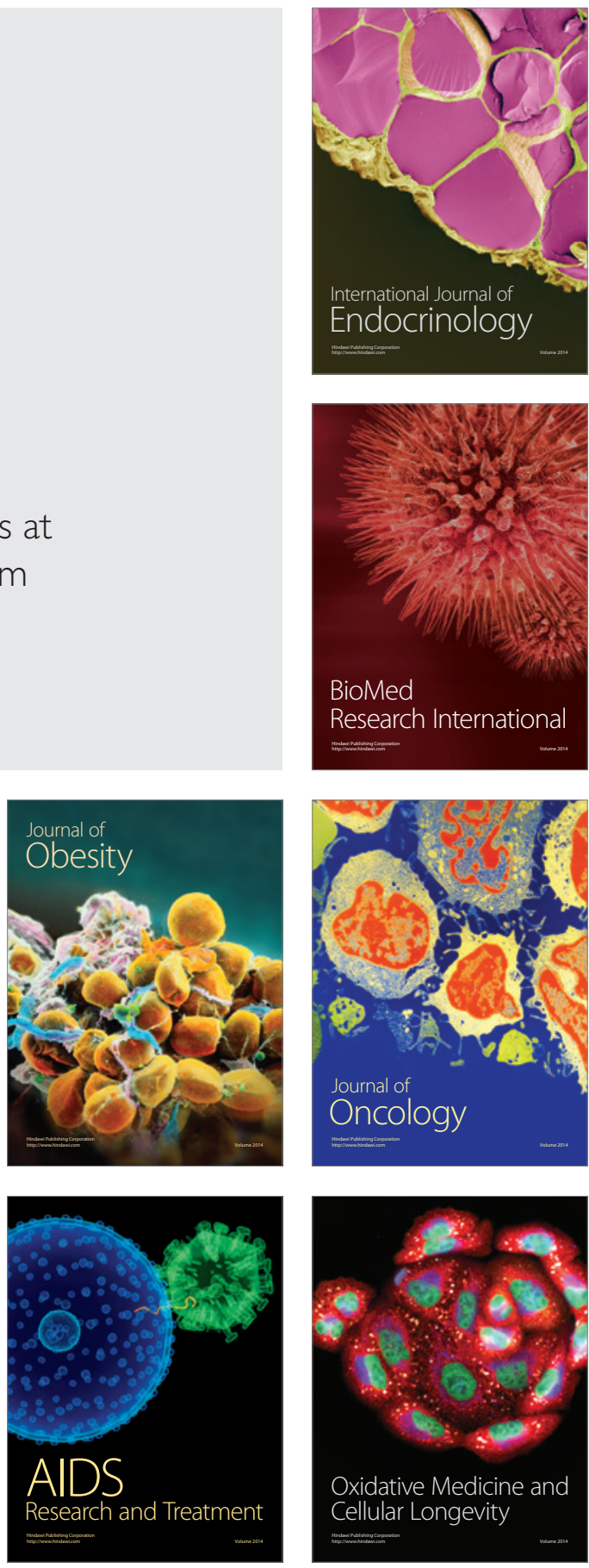